\title{
PERAMALAN INDEKS HARGA SAHAM GABUNGAN DENGAN METODE LOGISTIC SMOOTH TRANSITION AUTOREGRESSIVE (LSTAR)
}

\author{
Gayuh Kresnawati ${ }^{1}$, Budi Warsito ${ }^{2}$, Abdul Hoyyi ${ }^{3}$ \\ 1,2,3 Departemen Statistika, Fakultas Sains dan Matematika, Universitas Diponegoro \\ e-mail : budiwrst2@gmail.com
}

\begin{abstract}
Smooth Transition Autoregressive (STAR) Model is one of time series model used in case of data that has nonlinear tendency. STAR is an expansion of Autoregressive (AR) Model and can be used if the nonlinear test is accepted. If the transition function $\mathrm{G}(s t, \gamma, c)$ is logistic, the method used is Logistic Smooth Transition Autoregressive (LSTAR). Weekly IHSG data in period of 3 January 2010 until 24 December 2017 has nonlinier tend and logistic transition function so it can be modeled with LSTAR . The result of this research with significance level of 5\% is the LSTAR $(1,1)$ model. The forecast of IHSG data for the next 15 period has Mean Absolute Percentage Error (MAPE) 2,932612\%.
\end{abstract}

Keywords : autoregressive, LSTAR, nonlinier, time series

\section{PENDAHULUAN}

Indeks Harga Saham Gabungan (IHSG) merupakan salah satu indeks yang dikeluarkan oleh Bursa Efek Indonesia, pergerakan IHSG paling banyak dipublikasikan ke masyarakat baik itu melalui media elektronik berupa televisi maupun media cetak seperti koran dan juga melalui internet, sehingga IHSG merupakan indeks yang paling dikenal masyarakat.

Seorang investor harus memahami pola perilaku harga saham di pasar modal. Salah satu indeks yang sering diperhatikan investor ketika berinvestasi di Bursa Efek Indonesia adalah Indeks Harga Saham Gabungan. Hal ini disebabkan karena indeks ini merupakan composite index dari seluruh saham yang tercatat di Bursa Efek Indonesia. Oleh karena itu melalui pergerakan Indeks Harga Saham Gabungan, seorang investor dapat melihat kondisi pasar apakah sedang bergairah atau lesu. Perbedaan kondisi pasar ini memerlukan strategi yang berbeda dari investor dalam berinvestasi (Arifin, 2014).

Harga saham merupakan data runtun waktu dimana pergerakannya yang cenderung nonlinier membuat investor berpikir ulang untuk menjual atau menahan saham mereka. Oleh karena itu diperlukan metode khusus untuk meramalkan harga saham tersebut. Pemodelan Smooth Transition Autoregressive (STAR) dapat digunakan untuk kasus data runtun waktu nonlinier pada model Autoregressive. Model STAR telah menjadi model nonlinier yang populer dalam terapan bidang ekonomi modern menurut Terasvirta dan Anderson (1992). Wijk (1999) menjelaskan bahwa model STAR dibagi menjadi dua model berdasarkan fungsi transisinya yaitu Exponential Smooth Transition Autoregressive (ESTAR) dengan fungsi eksponensial dan Logistic Smooth Transition Autoregressive (LSTAR) dengan fungsi logistik. Metode LSTAR dalam penelitian sebelumnya oleh Triyono (2012) dapat digunakan untuk memodelkan data harga saham Bank Rakyat Indonesia, hal ini diperkuat dengan nilai MAPE yang relatif kecil yaitu 0,7676\%.

\section{TINJAUAN PUSTAKA}

\subsection{Indeks Harga Saham Gabungan (IHSG)}

Indeks Harga Saham Gabungan (IHSG) adalah suatu nilai yang digunakan untuk mengukur kinerja gabungan seluruh saham yang tercatat di bursa efek. Maksud dari 
gabungan seluruh saham ini adalah kinerja saham yang dimasukkan dalam perhitungan seluruh saham yang tercatat di bursa tersebut (Sunariyah, 2006).

\subsection{Return}

Return merupakan hasil yang diperoleh dari investasi atau tingkat keuntungan yang dinikmati oleh pemodal atas suatu investasi yang dilakukannya (Hartono, 2003).

Tsay (2005) merumuskan return sebagai berikut :

$X_{t}=\ln \left(\frac{P_{t}}{P_{t-1}}\right)$

dengan $P_{t} \quad=$ harga saham pada waktu ke-t

$P_{t-1} \quad=$ harga saham pada waktu t-1

\subsection{Analisis Runtun Waktu}

Runtun waktu (Time Series) merupakan serangkaian pengamatan terhadap suatu variabel yang diambil dari waktu ke waktu dan dicatat secara berurutan menurut urutan kejadiannya dengan interval waktu yang tetap (Wei, 2006).

\subsubsection{Stasioneritas}

Menurut Soejoeti (1987), runtun waktu $\left\{X_{t} ; t=1,2, \ldots, n\right\}$ dikatakan stasioner jika memenuhi sifat-sifat berikut :

a. $\mathrm{E}\left(\mathrm{X}_{\mathrm{t}}\right)=\mu$, konstan untuk setiap $\mathrm{t}$

b. $\operatorname{Var}\left(\mathrm{X}_{\mathrm{t}}\right)=\sigma^{2}$, konstan untuk setiap $\mathrm{t}$

c. $\operatorname{Cov}\left(\mathrm{X}_{\mathrm{t}}, \mathrm{X}_{\mathrm{t}+\mathrm{k}}\right)=\gamma_{k}$, konstan untuk setiap $\mathrm{t}$

dan $\gamma_{k}$ adalah autokovarian pada lag $\mathrm{k}$.

Time series plot dapat digunakan untuk mendeteksi secara visual kestasioneritasan data yaitu dengan jalan membuat plot terhadap data runtun waktu.

\section{Stasioneritas dalam Rata-rata}

Dalam Wei (2006) dijelaskan bahwa proses stasioner mempunyai nilai $|\phi|<1$. Selanjutnya dilakukan uji hipotesis dengan langkah sebagai berikut:

Hipotesis :

$\mathrm{H}_{0}:|\phi|=1$ (data tidak stasioner)

$\mathrm{H}_{1}:|\phi|<1$ (data stasioner)

Taraf signifikansi : $\alpha$

Statistik uji :

$$
\mathrm{DF}=\frac{\widehat{\phi}-1}{S E(\widehat{\phi})} \text {, dengan } \hat{\phi} \text { adalah estimator OLS dari } \phi
$$

Kriteria Penolakan :

$\mathrm{H}_{0}$ ditolak jika nilai statistik uji DF < nilai tabel distribusi kumulatif empiris dari $\mathrm{T}$ untuk $|\phi|=1$ atau $p$-value $<\alpha$.

\section{Stasioneritas dalam Varian}

Menurut Rosadi (2012), transformasi yang biasa digunakan untuk stasioneritas dalam varian adalah Box-Cox Transformation, dengan rumusannya adalah sebagai berikut: 
Tabel 1. Nilai $\lambda$ dan Fungsi Transformasi

\begin{tabular}{cc}
\hline Nilai $\lambda$ & Transformasi \\
\hline-1 & $\frac{1}{X_{t}}$ \\
$-0,5$ & $\frac{1}{\sqrt{X_{t}}}$ \\
0 & $\ln X_{t}$ \\
0,5 & $\sqrt{X_{t}}$ \\
2 & $X_{t}^{2}$ \\
\hline
\end{tabular}

\subsubsection{Fungsi Autokorelasi/ Autocorrelation Function (ACF)}

Menurut Wei (2006), suatu runtun waktu yang stasioner terdapat nilai mean $\mathrm{E}\left(\mathrm{X}_{\mathrm{t}}\right)=\mu$ dan varian $\operatorname{Var}\left(\mathrm{X}_{\mathrm{t}}\right)=\sigma^{2}$ yang konstan serta $\operatorname{Cov}\left(\mathrm{X}_{\mathrm{t}}, \mathrm{X}_{\mathrm{t}+\mathrm{k}}\right)$ dari sini dapat ditulis kovarian antara $X_{t}$ dan $X_{t+\mathrm{k}}$ adalah sebagai berikut :

$$
\gamma_{k}=\operatorname{Cov}\left(X_{t}, X_{t+k}\right)=E\left(X_{t}-\mu\right)\left(X_{t+k}-\mu\right),
$$

dan korelasi antara $X_{t}$ dan $X_{t+k}$ adalah :

$$
\rho_{k}=\frac{\operatorname{Cov}\left(X_{t}, X_{t+k}\right)}{\sqrt{\operatorname{Var}\left(X_{t}\right)} \sqrt{\operatorname{Var}\left(X_{t+k}\right)}}=\frac{\gamma_{k}}{\gamma_{0}}
$$

dengan $\operatorname{Var}\left(X_{t}\right)=\operatorname{Var}\left(X_{t+k}\right)=\gamma_{0}$.

\subsubsection{Fungsi Autokorelasi Parsial/ Partial Autocorrelation Function (PACF)}

Menurut Soejoeti (1987), fungsi autokorelasi parsial dapat ditulis dengan

$\left\{\phi_{\mathrm{kk}} ; \mathrm{k}=1,2, \ldots\right\}$ yaitu himpunan autokorelasi parsial untuk berbagai lag $\mathrm{k}$ yang kemudian didefinisikan sebagai berikut :

$$
\Phi_{\mathrm{kk}}=\frac{\left|\stackrel{\mathrm{\sim}}{\mathbf{P}} \mathbf{k}^{*}\right|}{|\sim \sim \mathbf{R}|}
$$

\subsection{Model Runtun Waktu Stasioner}

\subsubsection{Identifikasi Model}

Identifikasi model dalam runtun waktu stasioner terdiri dari model Autoregressive (AR), Moving Average (MA), dan Autoregressive Moving Average (ARMA).

a. Model Autoregressive (AR)

Menurut Soejoeti (1987), bentuk umum model Autoregressive (AR) dengan order $\mathrm{p}$ dinotasikan dengan $\operatorname{AR}(p)$ adalah :

$$
\mathrm{X}_{\mathrm{t}}=\phi_{1} \mathrm{X}_{t-1}+\phi_{2} \mathrm{X}_{t-2}+\ldots+\phi_{\mathrm{p}} \mathrm{X}_{\mathrm{t}-\mathrm{p}}+a_{t}, a_{t} \sim N\left(0, \sigma_{a}^{2}\right)
$$

b. Model Moving Average (MA)

Menurut Soejoeti (1987), model Moving Average dengan order q dinotasikan $\operatorname{MA}(q)$ didefinisikan sebagai:

$$
\mathrm{X}_{t}=a_{t}+\theta_{1} a_{t-1}+\theta_{2} a_{t-2}+\ldots+\theta_{q} a_{t-q} ; a_{t} \sim N\left(0, \sigma_{a}^{2}\right)
$$

c. Model Autoregressive Moving Average (ARMA)

Model Autoregressive Moving Average (ARMA) merupakan suatu perluasan yang diperoleh dari campuran antara model AR dan MA (Soejoeti, 1987).

Bentuk umum model $\operatorname{ARMA}(p, q)$ didefinisikan sebagai berikut

$$
X_{t}=\phi_{1} X_{t-1}+\cdots+\phi_{p} X_{t-p}+a t+\theta_{1} a_{t-1}+\ldots+\theta_{q} a_{t-q}
$$




\subsubsection{Estimasi Parameter}

Ada banyak metode untuk mengestimasi parameter model, namun pada umumnya estimasi parameter yang digunakan adalah Ordinary Least Square (OLS). Estimasi OLS merupakan estimasi yang meminimumkan jumlah kuadrat residual dari model berikut

$\mathrm{X}_{\mathrm{t}}=\phi \mathrm{X}_{t-1}+a_{t} \quad \mathrm{t}=1,2, \ldots, \mathrm{n}$

Maka estimator OLS dari $\phi$ berdasarkan persamaan tersebut adalah :

$\hat{\phi}=\frac{\sum_{\mathrm{t}=1}^{\mathrm{n}} \mathrm{x}_{t-1} \mathrm{X}_{\mathrm{t}}}{\sum_{\mathrm{t}=1}^{\mathrm{n}} \mathrm{x}_{t-1}^{2}}$

\subsubsection{Pengujian Parameter Model}

Untuk menguji apakah parameter yang telah diidentifikasi signifikan atau tidak maka selanjutnya dilakukan pengujian terhadap parameter model dengan hipotesis sebagai berikut :

a. $\quad$ Model $\operatorname{AR}(p)$

Hipotesis :

$\mathrm{H}_{0}: \phi_{\mathrm{j}}=0$ (parameter tidak signifikan)

$\mathrm{H} 1: \phi_{\mathrm{j}} \neq 0$ (parameter signifikan), $\mathrm{j}=1,2, \ldots, \mathrm{p}$

Taraf signifikansi : $\alpha$

Statistik Uji :

$$
t_{\text {hit }}=\frac{\widehat{\phi}_{\mathrm{j}}}{\operatorname{se}\left(\widehat{\phi}_{\mathrm{j}}\right)} \text {, dengan } \operatorname{se}\left(\hat{\phi}_{\mathrm{j}}\right) \text { adalah standard error dari } \widehat{\phi}_{\mathrm{j}}
$$

Kriteria Penolakan :

Tolak $\mathrm{H}_{0}$ jika nilai statistika $\mathrm{t}_{\text {hit }}>$ nilai tabel $\frac{\mathrm{t}_{\frac{\alpha}{2}}(n-p)}{\text { atau nilai }}$ $p$-value $<\alpha$

b. $\quad \operatorname{Model} \operatorname{MA}(q)$

Hipotesis :

$\mathrm{H}_{0}: \theta_{\mathrm{i}}=0$ (parameter tidak signifikan)

$\mathrm{H}_{1}: \theta_{\mathrm{i}} \neq 0$ (parameter signifikan), $\mathrm{i}=1,2, \ldots, q$

Taraf signifikansi : $\alpha$

Statistik Uji :

$t_{\text {hit }}=\frac{\hat{\theta}_{\mathrm{i}}}{\operatorname{se}\left(\hat{\theta}_{\mathrm{i}}\right)}$, dengan $\operatorname{se}\left(\hat{\theta}_{\mathrm{i}}\right)$ adalah standard error dari $\hat{\theta}_{\mathrm{i}}$

Kriteria Penolakan :

Tolak $\mathrm{H}_{0}$ jika nilai statistika $\mathrm{t}_{\text {hit }}>$ nilai tabel $\frac{\mathrm{t} \alpha}{2}(n-q)$ atau nilai $p$-value $<\alpha$.

\subsection{Pemilihan Model Terbaik}

Model terbaik dapat dipilih berdasarkan nilai Akaike Info Criterion (AIC). Dijk (1999) merumuskan AIC sebagai berikut :

$$
A I C=n \ln \hat{\sigma}_{a}^{2}+2 p
$$

dengan $\hat{\sigma}_{a}^{2}=\sum_{t=1}^{T} \hat{a}_{t}^{2}, \hat{a}_{t}$ adalah residual dari estimasi model dan $\mathrm{p}$ adalah banyaknya parameter model. Model terbaik dipilih dari model dengan nilai AIC terkecil.

\subsection{Pemeriksaan Diagnostik}

\subsubsection{Uji Autokorelasi Residual}

Menurut Wei (2006), untuk menguji apakah residual independen atau tidak digunakan metode L-Jung Box sebagai berikut:

Hipotesis : 
$\mathrm{H}_{0}: \rho_{1}=\rho_{2}=\cdots=\rho_{K}=0$ (tidak ada korelasi residual antar lag)

$\mathrm{H}_{1}$ : paling sedikit ada satu nilai $\rho_{k} \neq 0$ (ada korelasi residual antar lag), untuk $\mathrm{k}=1,2, \ldots, K$

Taraf signifikansi : $\alpha$

Statistik Uji :

$$
Q=n(n+2) \sum_{k=1}^{K}(n-k)^{-1} \hat{\rho}_{k}^{2}
$$

Kriteria Penolakan :

Tolak $\mathrm{H}_{0}$ jika nilai $Q>\chi_{(\alpha, K-p-q)}^{2}$, dengan $K$ adalah lag tertinggi, $p$ adalah orde dari model AR, dan $q$ adalah orde dari model MA.

\subsubsection{Uji Homoskedastisitas Residual}

Menurut William (1993), salah satu cara untuk mendeteksi adanya proses ARCH adalah uji Lagrange Multiplier yaitu dengan cara meregresikan kuadrat dari residual model Hipotesis :

$$
\sigma_{t}^{2}=\alpha_{0}+\alpha_{1} a_{t-1}^{2}+\alpha_{2} a_{t-2}^{2}+\cdots+\alpha_{k} a_{t-k}^{2}
$$

$\mathrm{H}_{0}: \alpha_{1}=\alpha_{2}=\cdots=\alpha_{k}=0$ (tidak ada efek ARCH)

$\mathrm{H} 1$ : paling sedikit ada satu $\alpha_{\mathrm{j}} \neq 0$, dengan $\mathrm{j}=1,2, . ., \mathrm{k}$ (ada efek ARCH)

Taraf signifikansi : $\alpha$

Statistik Uji :

$$
\mathrm{LM}=\mathrm{nR}^{2}, \text { dengan } \mathrm{R}^{2}=\frac{\mathrm{JKR}}{\mathrm{JKT}}=\frac{\sum_{\mathrm{t}=1}^{\mathrm{T}}\left(\widehat{\mathrm{X}}_{\mathrm{t}}-\overline{\mathrm{X}}\right)^{2}}{\sum_{\mathrm{t}=1}^{\mathrm{T}}\left(\mathrm{X}_{\mathrm{t}}-\overline{\mathrm{X}}\right)^{2}}
$$

Kriteria Penolakan :

Tolak H0 jika nilai statistika $\mathrm{LM}>\chi_{\mathrm{k}}^{2}$.

\subsection{Model Smooth Transition Autoregressive (STAR)}

Model Smooth Transition Autoregressive (STAR) merupakan salah satu model runtun waktu nonlinier perluasan dari model Autoregressive (AR). Dijk (1999) menuliskan model STAR sebagai berikut :

$$
X_{t}=\boldsymbol{\phi}_{\mathbf{1}}^{\prime} \boldsymbol{Z}_{\boldsymbol{t}}\left(1-G\left(s_{t}, \gamma, c\right)\right)+\boldsymbol{\phi}_{2}^{\prime} \boldsymbol{Z}_{\boldsymbol{t}} G\left(s_{t}, \gamma, c\right)+\varepsilon_{t}
$$

\subsubsection{Logistic Smooth Transition Autoregressive (LSTAR)}

Menurut Terasvirta (1994), fungsi transisi logistik dapat ditulis sebagai berikut :

$G\left(s_{t}, \gamma, c\right)=\frac{1}{1+\exp \left(-\gamma\left(s_{t}-c\right)\right)}, \gamma>0$

maka diperoleh model LSTAR yaitu :

$$
X_{t}=\boldsymbol{\phi}_{\mathbf{1}}^{\prime} \boldsymbol{Z}_{\boldsymbol{t}}\left(1-\left(\frac{1}{1+\exp \left(-\gamma\left(s_{t}-c\right)\right)}\right)\right)+\boldsymbol{\phi}_{\mathbf{2}}^{\prime} \boldsymbol{Z}_{\boldsymbol{t}}\left(\frac{1}{1+\exp \left(-\gamma\left(s_{t}-c\right)\right)}\right)+\varepsilon_{t}
$$

\subsubsection{Exponential Smooth Transition Autoregressive (ESTAR)}

Fungsi transisi eksponensial menurut Terasvirta (1994) yaitu sebagai berikut :

$$
G\left(s_{t}, \gamma, c\right)=1-\exp \left(-\gamma\left(s_{t}-c\right)^{2}\right), \gamma>0
$$

sehingga diperoleh model ESTAR yaitu :

$$
X_{t}=\boldsymbol{\phi}_{1}^{\prime} \boldsymbol{Z}_{\boldsymbol{t}}\left(1-\left(1-\exp \left(-\gamma\left(s_{t}-c\right)^{2}\right)\right)\right)+\boldsymbol{\phi}_{2}^{\prime} \boldsymbol{Z}_{\boldsymbol{t}}\left(1-\exp \left(-\gamma\left(s_{t}-c\right)^{2}\right)\right)+\varepsilon_{t}
$$

\subsection{Pengujian Nonlinieritas}

Hipotesis nol pengujian nonlinieritas model STAR berikut yaitu:

$$
X_{t}=\boldsymbol{\phi}_{\mathbf{1}}^{\prime} \boldsymbol{Z}_{\boldsymbol{t}}+\left(\boldsymbol{\phi}_{\mathbf{2}}^{\prime}-\boldsymbol{\phi}_{\mathbf{1}}^{\prime}\right) \boldsymbol{Z}_{\boldsymbol{t}} G\left(s_{t}, \gamma, c\right)+\varepsilon_{t}
$$


Hipotesis :

$\mathrm{H}_{0}: \boldsymbol{\phi}_{\mathbf{1}}=\boldsymbol{\phi}_{\mathbf{2}}$ (model linier)

$\mathrm{H}_{1}: \boldsymbol{\phi}_{\mathbf{1}} \neq \boldsymbol{\phi}_{\mathbf{2}}$ (model nonlinier)

Taraf signifikansi : $\alpha$

Statistik Uji :

$$
\mathrm{LM}_{3}=\mathrm{n} \frac{\left(\mathrm{SSR}_{0}-\mathrm{SSR}_{1}\right)}{\mathrm{SSR}_{0}} \text {, dengan } \mathrm{n} \text { adalah ukuran sampel }
$$

Kriteria Penolakan :

Tolak $\mathrm{H}_{0}$ jika nilai $L M_{3}>\chi_{3 p}^{2}$, model STAR dapat digunakan jika uji nonlinieritas terpenuhi.

\subsection{Pemilihan Fungsi Transisi}

Langkah selanjutnya adalah menentukan bentuk dari fungsi transisi $G\left(s_{t}, \gamma, c\right)$ dengan menguji urutan hipotesis nol dari model regresi bantu berikut :

Hipotesis :

$$
a_{t}=\beta_{0,0}+\beta_{0}^{\prime} \widetilde{X}_{t}+\beta_{1}^{\prime} \widetilde{X}_{t} s_{t}+\beta_{2}^{\prime} \widetilde{X}_{t} s_{t}^{2}+\beta_{3}^{\prime} \widetilde{X}_{t} s_{t}^{3}+e_{t}
$$

$\mathrm{H}_{0}: \beta_{3, i}=0$ (fungsi transisi eksponensial)

$\mathrm{H}_{1}: \beta_{3, i} \neq 0$ (fungsi transisi logistik), dengan $\mathrm{i}=1,2$

Taraf signifikan : $\alpha$

Statistik Uji :

$$
t_{\text {hit }}=\frac{\widehat{\beta}_{3, i}}{\operatorname{se}\left(\widehat{\beta}_{3, i}\right)}
$$

Kriteria Penolakan :

Tolak $\mathrm{H}_{0}$ jika nilai $\left|t_{h i t}\right| \geq \mathrm{t}_{\frac{\alpha}{2}(n-p)}$ atau nilai $p$-value $<\alpha$.

\subsection{Estimasi Parameter Model STAR}

Dijk (1999) menggunakan metode Nonlinier Least Square (NLS) untuk mengestimasi parameter dari model $\operatorname{STAR}(p, d)$ dengan meminimumkan jumlah kuadrat residual yang didefinisikan sebagai berikut :

dengan

$$
\hat{\theta}=\operatorname{argmin} \sum_{t=1}^{T}\left(X_{t}-F\left(Z_{t} ; \theta\right)\right)^{2}
$$

$$
F\left(Z_{t}, \theta\right)=\boldsymbol{\phi}_{\mathbf{1}}^{\prime} \boldsymbol{Z}_{\boldsymbol{t}}\left(1-G\left(s_{t}, \gamma, c\right)\right)+\boldsymbol{\phi}_{\mathbf{2}}^{\prime} \boldsymbol{Z}_{\boldsymbol{t}} G\left(s_{t}, \gamma, c\right)
$$

Proses pencarian nilai parameter pada metode NLS ini dilakukan dengan menggunakan metode numerik yaitu metode Gauss-Newton untuk melakukan estimasi secara iterasi.

\subsection{Evaluasi Hasil Peramalan}

Menurut Dijk (1999), ukuran yang digunakan untuk evaluasi hasil peramalan salah satunya adalah dengan Mean Absolute Percentage Error (MAPE). Semakin kecil MAPE maka peramalan yang dihasilkan semakin baik. MAPE dirumuskan sebagai:

$$
M A P E=\frac{1}{n} \sum_{t=1}^{n}\left|\left(\frac{P_{t}-\hat{P}_{t}}{P_{t}}\right) x 100 \%\right|
$$

\section{METODOLOGI PENELITIAN}

\subsection{Sumber Data}

Data yang digunakan dalam penelitian ini adalah data sekunder tentang Indeks Harga Saham Gabungan mingguan yang diambil dari website http://finance.yahoo.com periode 3 Januari 2010 sampai dengan 24 Desember 2017. 


\subsection{Metode Analisis}

Langkah-langkah yang ditempuh untuk mencapai tujuan penelitian ini adalah sebagai berikut :

1. Menghitung nilai return data Indeks Harga Saham Gabungan (IHSG)

2. Melakukan pengujian stasioneritas dari data return IHSG

3. Mengidentifikasi model runtun waktu stasioner

4. Melakukan estimasi parameter

5. Pengujian model terbaik AR

6. Melakukan pengujian asumsi autokorelasi dan homoskedastisitas dari residual model $\operatorname{AR}(p)$. Orde model AR yang terbentuk akan digunakan dalam pengujian nonlinieritas pada model STAR.

7. Menentukan fungsi transisi

8. Estimasi model LSTAR

9. Pemodelan LSTAR

10. Meramalkan nilai return menggunakan model LSTAR untuk mencari nilai ramalan IHSG

\section{HASIL DAN PEMBAHASAN}

4.1. Deskripsi Data

Data harga saham terkecil terletak pada minggu ke 5 yaitu sebesar 2518,976 dan harga saham terbesar terletak pada minggu ke 414 yaitu sebesar 6355,654, data berfluktuasi dari waktu ke waktu yang mengindikasikan bahwa data tidak stasioner.

\subsection{Return}

Data Indeks Harga Saham Gabungan mingguan periode 3 Januari 2010 sampai 24 Desember 2017 tidak stasioner. Sedangkan data return memperlihatkan data sudah stasioner, karena rata-rata dari plot return terlihat konstan, indikasi bahwa data sudah stasioner juga dapat ditunjukkan pada plot ACF dan PACF, plot ACF dan PACF pada lag pertama turun secara cepat mendekati nol, sehingga data stasioner.

\subsection{Pengujian Stasioneritas} Stasioneritas dalam Varian

Data return saham mempunyai nilai negatif dan nol sehingga dilakukan penambahan sebesar 0,17386 sesuai dengan nilai terkecil pada data return. Rounded Value yang diperoleh dari data return IHSG adalah 1, sehingga data telah stasioner dalam varian.

\section{Stasioneritas dalam Rata-rata}

Hipotesis uji DF adalah

Hipotesis :

$\mathrm{H}_{0}:|\phi|=1$ (data tidak stasioner)

$\mathrm{H}_{1}:|\phi|<1$ (data stasioner)

Nilai statistik uji DF yang dihasilkan adalah -4,378914. Dengan menggunakan $\alpha$ sebesar 5\% nilai kritis DF $=-1,941602$. Dari hasil tersebut dapat disimpulkan bahwa nilai statistik uji DF lebih kecil dari nilai kritis DF yang artinya menolak $\mathrm{H}_{0}$ yaitu data stasioner.

\subsection{Identifikasi Model}

Dalam tahap idenfitikasi model digunakan fungsi autokorelasi/ Autocorrelation Function (ACF) dan fungsi autokorelasi parsial/ Partial Autocorrelation Function (PACF). Pada lag pertama plot ACF dan PACF keluar dari interval konfidensi maka model yang akan terbentuk adalah $\mathrm{AR}(1), \mathrm{MA}(1)$, dan $\operatorname{ARMA}(1,1)$. 


\subsection{Estimasi dan Pengujian Parameter Model}

Selanjutnya dilakukan estimasi terhadap parameter model AR(1), MA(1), dan ARMA $(1,1)$ dengan menggunakan metode Ordinary Least Square (OLS).

Tabel 2. Estimasi Parameter Model AR(1), MA(1), dan ARMA(1,1)

\begin{tabular}{ccccc}
\hline Model & Koefisien & t hitung & Probabilitas & Keputusan \\
\hline AR(1) & $-0,164217$ & $-4,103523$ & 0,0000 & Signifikan \\
MA(1) & $-0,153040$ & $-3,587279$ & 0,0004 & Signifikan \\
ARMA(1,1) & $-0,197064$ & $-0,898239$ & 0,3696 & Tidak Signifikan \\
& 0,033705 & 0,145507 & 0,8844 & Tidak Signifikan \\
\hline
\end{tabular}

\subsection{Pemilihan Model Terbaik}

Pada penelitian ini kriteria yang digunakan untuk menentukan model terbaik yaitu parameter-parameternya signifikan dan mempunyai nilai AIC terkecil.

Tabel 3. Hasil Pengujian Parameter Model dan Nilai AIC

\begin{tabular}{ccc} 
Model & Uji Signifikansi & AIC \\
\hline AR(1) & Signifikan & $-3,169962$ \\
MA(1) & Signifikan & $-3,168302$ \\
ARMA(1,1) & Tidak Signifikan & $-3,165183$ \\
\hline
\end{tabular}

Model AR(1) adalah model terbaik karena untuk uji signifikansi, parameter model signifikan dan memiliki nilai AIC terkecil yaitu sebesar -3,169962.

\subsection{Uji Asumsi}

\subsubsection{Uji Autokorelasi Residual}

Hipotesis Ljung-Box adalah sebagai berikut: Hipotesis :

$\mathrm{H}_{0}: \rho_{1}=\rho_{2}=\cdots=\rho_{K}=0$ (tidak ada korelasi residual antar lag)

$\mathrm{H}_{1}$ : paling sedikit ada satu nilai $\rho_{k} \neq 0$ (ada korelasi residual antar lag), untuk $\mathrm{k}=1,2, \ldots, \mathrm{K}$

Dengan menggunakan $\alpha=5 \%$ diperoleh nilai $\chi_{(0,05 ; 21)}^{2}$ sebesar 32,671 , nilai Q-stat sampai lag ke 22 lebih kecil dari nilai $\chi_{(0,05 ; 21)}^{2}$ yang artinya menerima $\mathrm{H}_{0}$ yaitu tidak ada korelasi di dalam residual model AR(1) sampai lag ke 22.

\subsubsection{Uji Homoskedastisitas Residual}

Hipotesis Uji Homoskedastisitas adalah sebagai berikut: Hipotesis :

$\mathrm{H}_{0}: \alpha_{1}=\alpha_{2}=\cdots=\alpha_{k}=0$ (tidak ada efek ARCH)

$\mathrm{H}_{1}$ : paling sedikit ada satu $\alpha_{j} \neq 0$, dengan $\mathrm{j}=1,2, . ., \mathrm{k}$ (ada efek $\left.\mathrm{ARCH}\right)$

Nilai statistik uji LM test sebesar 1,047849, dengan menggunakan $\alpha$ 5\% diperoleh nilai $\chi_{(0,05 ; 1)}^{2}$ sebesar 3,841 , sehingga dapat disimpulkan bahwa nilai statistik uji LM test lebih kecil dari nilai tabel $\chi_{(0,05 ; 1)}^{2}$ yang artinya terima $\mathrm{H}_{0}$ yaitu tidak ada efek $\mathrm{ARCH}$.

\subsection{Pemodelan Awal Smooth Transition Autoregressive (STAR)}

Orde model STAR diperoleh berdasarkan orde model AR(1) atau orde $p=1$ sehingga variabel transisi dalam model STAR adalah $s_{t}=X_{t-1}$. Model $\operatorname{STAR}(1,1)$ berdasarkan persamaan (4) dapat ditulis sebagai berikut:

$$
X_{t}=\left(\phi_{1,0}+\phi_{1,1} X_{t-1}\right)\left(1-G\left(s_{t}, \gamma, c\right)\right)+\left(\phi_{2,0}+\phi_{2,1} X_{t-1}\right) G\left(s_{t}, \gamma, c\right)+\varepsilon_{t}
$$
dengan $G\left(s_{t}, \gamma, c\right)$ adalah fungsi transisi. 


\subsection{Uji Nonlinieritas dan Fungsi Transisi}

Asumsi nonlinieritas dapat diuji menggunakan statistik Lagrange Multiplier (LM) dengan hasil sebagai berikut:

Tabel 4. Hasil Pengujian Nonlinieritas dengan Variabel Transisi $s_{t}=X_{t-1}$

\begin{tabular}{ccc} 
Model & LM statistic & Probabilitas \\
\hline ESTAR & 0,441 & 0,802 \\
LSTAR & 15,027 & 0,002 \\
\hline
\end{tabular}

Hipotesis pengujian nonlinieritas yaitu:

\section{Pengujian ESTAR}

Hipotesis

$\mathrm{H}_{0}: \phi_{\mathbf{1}}=\boldsymbol{\phi}_{\mathbf{2}}$ (model linier)

$\mathrm{H}_{1}: \boldsymbol{\phi}_{\mathbf{1}} \neq \boldsymbol{\phi}_{\mathbf{2}}$ (model yang sesuai ESTAR)

Berdasarkan tabel 4 diperoleh bahwa model ESTAR memiliki statistik uji $\mathrm{LM}_{3}$ yaitu 0,441 , dengan $\alpha$ sebesar $5 \%$ nilai tabel Chi-square $\left(\chi_{(0,05 ; 3)}^{2}=7,815\right)$, dapat disimpulkan bahwa nilai statistik $\mathrm{LM}_{3}$ lebih kecil dari nilai tabel Chi-square yang artinya menerima $\mathrm{H}_{0}$ dan model yang sesuai adalah model linier.

\section{Pengujian LSTAR}

Hipotesis

$\mathrm{H}_{0}: \phi_{1}=\phi_{2}$ (model linier)

$\mathrm{H}_{1}: \boldsymbol{\phi}_{\mathbf{1}} \neq \boldsymbol{\phi}_{\mathbf{2}}$ (model yang sesuai LSTAR)

Berdasarkan tabel 4 diperoleh bahwa model LSTAR memiliki statistik uji $\mathrm{LM}_{3}$ yaitu 15,027 , dengan $\alpha$ sebesar $5 \%$ nilai tabel Chi-square $\left(\chi_{(0,05 ; 3)}^{2}=7,815\right)$, dapat disimpulkan bahwa nilai statistik $\mathrm{LM}_{3}$ lebih besar dari nilai tabel Chi-square yang artinya menolak $\mathrm{H}_{0}$ dan model yang sesuai adalah model LSTAR.

\section{Fungsi Transisi Logistik}

Model yang terpilih adalah model Logistic Smooth Transition Autoregressive (LSTAR) dimana fungsi transisi logistik menurut Terasvirta (1994) yaitu:

$$
G\left(s_{t}, \gamma, c\right)=\frac{1}{1+\exp \left(-\gamma\left(s_{t}-c\right)\right)}, \gamma>0
$$

Model awal LSTAR $(1,1)$ yaitu sebagai berikut:

$$
X_{t}=\left(\phi_{1,0}+\phi_{1,1} X_{t-1}\right)\left(1-\left(\frac{1}{1+\exp \left(-\gamma\left(s_{t}-c\right)\right)}\right)\right)+\left(\phi_{2,0}+\phi_{2,1} X_{t-1}\right)\left(\frac{1}{1+\exp \left(-\gamma\left(s_{t}-c\right)\right)}\right)+
$$

\subsection{Estimasi Parameter Model LSTAR (1,1)}

Estimasi model LSTAR(1,1) menggunakan metode Nonlinier Least Square (NLS) yang didekati dengan iterasi Gauss-Newton, selanjutnya diestimasi ulang dengan sistem Try and Error yakni mengilangkan parameter yang tidak signifikan dan membandingkan nilai AIC dan MAPE yang diperoleh. 
Tabel 5. Nilai AIC Model LSTAR

\begin{tabular}{lc}
\hline \multicolumn{1}{c}{ Model } & AIC \\
\hline LSTAR(1,1) & $-3,194866$ \\
LSTAR(1,1) tanpa $\phi_{1,1}$ & $-3,197513$ \\
LSTAR(1,1) tanpa $\phi_{2,0}$ & $-3,180711$ \\
LSTAR(1,1) tanpa $\gamma$ & $-3,171047$ \\
\hline
\end{tabular}

Model LSTAR $(1,1)$ tanpa parameter $\phi_{1,1}$ adalah model terbaik karena memiliki nilai AIC terkecil yaitu -3,197513. Model LSTAR yang dapat digunakan adalah Model $\operatorname{LSTAR}(1,1)$ dan Model LSTAR $(1,1)$ tanpa parameter $\phi_{1,1}$ karena parameter-parameter dari fungsi transisi $G\left(s_{t}, \gamma, c\right)$ signifikan.

\subsection{Model LSTAR(1,1)}

Model LSTAR $(1,1)$ yang diperoleh berdasarkan estimasi parameter di bagian 4.10 yaitu sebagai berikut:

\section{Model LSTAR(1,1)}

$$
\begin{aligned}
X_{t}= & (0,008622)\left(1-\left(\frac{1}{1+\exp \left(-\left(X_{t-1}-0,161794\right)\right)}\right)\right)+ \\
& \left(1,731463 X_{t-1}\right)\left(\frac{1}{1+\exp \left(-\left(X_{t-1}-0,161794\right)\right)}\right)
\end{aligned}
$$

\section{Model LSTAR(1,1) Tanpa Parameter $\phi_{1,1}$}

$$
\begin{aligned}
X_{t}= & (0,011617)\left(1-\left(\frac{1}{1+\exp \left(-31,58354\left(X_{t-1}-0,163233\right)\right)}\right)\right)+(-0,482701+ \\
& \left.1,834902 X_{t-1}\right)\left(\frac{1}{1+\exp \left(-31,58354\left(X_{t-1}-0,163233\right)\right)}\right)
\end{aligned}
$$

dengan $X_{t}$ adalah nilai return pada waktu ke-t.

\subsection{Evaluasi Hasil Peramalan}

Nilai Mean Absolute Percentage Error (MAPE) hasil ramalan kedua model LSTAR(1,1) untuk 15 periode berikutnya yaitu:

Tabel 6. Nilai MAPE Model LSTAR

\begin{tabular}{lc}
\hline \multicolumn{1}{c}{ Model } & AIC \\
\hline LSTAR(1,1) & $19,604802 \%$ \\
LSTAR(1,1) tanpa $\phi_{1,1}$ & $5,801193 \%$ \\
\hline
\end{tabular}

Model terbaik LSTAR dipilih berdasarkan nilai AIC dan MAPE yang diperoleh dari masing-masing model. Oleh karena itu model terbaik yang dipilih adalah model LSTAR $(1,1)$ tanpa parameter $\square_{1,1}$ karena memiliki nilai AIC dan MAPE yang paling kecil. Model LSTAR(1,1) Tanpa Parameter

$$
\begin{aligned}
& =(0,011617)\left(1-\left(\frac{1}{1+\exp \left(-31,58354\left(\square_{\square-1}-0,163233\right)\right)}\right)\right)+(-0,482701+ \\
& \left.1,834902 \square_{\square-1}\right)\left(\frac{1}{1+\exp \left(-31,58354\left(\square_{\square-1}-0,163233\right)\right)}\right)
\end{aligned}
$$




\section{PENUTUP}

\subsection{Kesimpulan}

Kesimpulan yang dapat diambil dari hasil analisis dan pembahasan pada penelitian ini adalah sebagai berikut:

1. Model LSTAR $(1,1)$ tanpa parameter $\phi_{1,1}$ adalah model terbaik yang diperoleh untuk memodelkan data Indeks Harga Saham Gabungan yang terlebih dahulu ditransformasikan dalam bentuk return. Model yang diperoleh adalah

$$
\begin{aligned}
& =(0,011617)\left(1-\left(\frac{1}{1+\exp \left(-31,58354\left(\square_{\square-1}-0,163233\right)\right)}\right)\right)+(-0,482701+ \\
& \left.1,834902 \square_{\square-1}\right)\left(\frac{1}{1+\exp \left(-31,58354\left(\square_{\square-1}-0,163233\right)\right)}\right)
\end{aligned}
$$

dengan $X_{t}$ adalah return pada periode ke-t.

2. Hasil peramalan Indeks Harga Saham Gabungan untuk 15 periode ke depan mendekati data aslinya. Hal ini ditunjukkan dengan nilai MAPE yang relatif kecil yaitu sebesar $5,801193 \%$.

\subsection{Saran}

Kajian penelitian lebih lanjut dapat dikembangkan untuk pemodelan heteroskedastisitas model runtun waktu nonlinear yaitu model Smooth Transition Autoregressive Conditional Heteroscedastic (STARCH).

\section{DAFTAR PUSTAKA}

Arifin, M. 2014. Pengaruh Inflasi, Suku Bunga SBI, Perubahan Kurs, dan Standard \& Poor's 500 Terhadap Indeks Harga Saham Gabungan. Jurnal Fakultas Ekonomi Universitas Yogyakarta

Dickey, D.A., dan Fuller, W. A. 1979. Distribution of the Estimators for Autoregressive Time Series with a Unit Root. Journal of the American Statistical Association 74 (366): 427-431

Dijk, V. 1999. Smooth Transition Models : Extensions and Outliers Robust Inference. Tinberg Institute : Amsterdam

Jogiyanto, Hartono. 2003. Teori Portofolio dan Analisis Investasi Edisi Kelima. Yogyakarta. Bpfe.

Makridakis, S. Whellwright, S. C., dan McGee, V. E. 1992. Metode dan Aplikasi Peramalan. Erlangga : Jakarta

Rosadi, D. 2012. Ekonometrika \& Analisis Runtun Waktu Terapan dengan EViews. Andi : Yogyakarta

Soejoeti, Z. 1987. Analisis Runtun Waktu. Universitas Terbuka : Karunia Jakarta

Sunariyah. 2006. Pengantar Pengetahuan Pasar Modal. Edisi Kelima, UPP STIM YKPN, Yogyakarta

Terasvirta, T. 1994. Specification, Estimation, and Evaluation of Smooth Transition Autoregressive Models. Journal of the American Statistical Association, Vol. 89 : 425

Terasvirta, T., Dijk, dan Marcelo. 2005. Linear Models, Smooth Transition Autoregressions, and Neural Networks for Forecasting Macroeconomic Time Series : A Re-examination. International Journal of Forecasting, Vol. 21 : 755-774

Terasvirta, T., dan Anderson, H. 1992. Characterizing Nonlinearities in Business Cycles Using Smooth Transition Autoregressive Models. Journal of Applied Econometrics, Vol. $7: 119-136$ 
Triyono. 2012. Peramalan Harga Saham Bank Rakyat Indonesia Menggunakan Model Logistic Smooth Transition Autoregressive (LSTAR). Skripsi. Fakultas Matematika dan Ilmu Pengetahuan Alam Universitas Sebelas Maret : Surakarta

Tsay, R. S. 2005. Analysis of Financial Time Series . John Wiley \& Sons, Inc : Canada.

Wei, W.W.S. 2006. Time Series Analysis : Univariate and Multivariate Methods. AddisonWesley Publishing Company-Inc : USA

William, H. G. 1993. Econometric Analysis. Pearson Education, Inc : New Jersey

Yanuar, AY. 2013. Dampak Variabel Internal Dan Eksternal Terhadap Indeks Harga Saham Gabungan (IHSG) Di Indonesia. Jurnal Fakultas Ekonomi dan Bisnis Universitas Brawijaya Malang.

[BEI]. Bursa Efek Indonesia. 2018. www.idx.co.id diakses pada tanggal 20 Mei 2018 jam $10.56 \mathrm{WIB}$ 